\title{
Seed Dispersal Potential of Asian Elephants
}

Harich, Franziska K. ; Treydte, Anna Christina; Ogutu, Joseph Ochieng; Roberts, John E.; Savini, Chution; Bauer, Jan Michael; Savini, Tommaso

\author{
Document Version \\ Accepted author manuscript \\ Published in: \\ Acta Oecologica \\ DOI: \\ 10.1016/j.actao.2016.10.005 \\ Publication date: \\ 2016 \\ License \\ CC BY-NC-ND
}

Citation for published version (APA):

Harich, F. K., Treydte, A. C., Ogutu, J. O., Roberts, J. E., Savini, C., Bauer, J. M., \& Savini, T. (2016). Seed Dispersal Potential of Asian Elephants. Acta Oecologica, 77, 144-151.

https://doi.org/10.1016/j.actao.2016.10.005

Link to publication in CBS Research Portal

\section{General rights}

Copyright and moral rights for the publications made accessible in the public portal are retained by the authors and/or other copyright owners and it is a condition of accessing publications that users recognise and abide by the legal requirements associated with these rights.

Take down policy

If you believe that this document breaches copyright please contact us (research.lib@cbs.dk) providing details, and we will remove access to the work immediately and investigate your claim. 


\title{
Seed Dispersal Potential of Asian Elephants \\ Franziska K. Harich, Anna Christina Treydte, Joseph Ochieng Ogutu, John E. Roberts, Chution Savini, Jan Michael Bauer, and Tommaso Savini \\ Journal article (Accepted version)
}

\begin{abstract}
CITE: Seed Dispersal Potential of Asian Elephants. / Harich, Franziska K. ; Treydte, Anna Christina; Ogutu, Joseph Ochieng; Roberts, John E.; Savini, Chution; Bauer, Jan Michael; Savini, Tommaso. In: Acta Oecologica, Vol. 77, 2016, p. 144-151.
\end{abstract}

DOI: 10.1016/j.actao.2016.10.005

Uploaded to Research@CBS: March २०18

(C) 2018. This manuscript version is made available under the CC-BY-NC-ND 4.0 license http://creativecommons.org/licenses/by-nc-nd/4.0/ 


\section{Seed dispersal potential of Asian Elephants}

Franziska K. Harich ${ }^{a}$, Anna C. Treydte ${ }^{a 1}$, Joseph O. Ogutu ${ }^{b}$, John E. Roberts ${ }^{c}$, Chution

Savini $^{d}$, Jan M. Bauer ${ }^{e 2}$, Tommaso Savinif

${ }^{a}$ Department of Agroecology in the Tropics and Subtropics, University of Hohenheim, Garbenstr. 13, 70593 Stuttgart, Germany. Email: harich@uni-hohenheim.de, anna@treydte.com

${ }^{\mathrm{b}}$ Biostatistics Unit, University of Hohenheim, Fruwirthstr. 23, 70593 Stuttgart, Germany. Email: jogutu2007@gmail.com

${ }^{\mathrm{c}}$ Golden Triangle Asian Elephant Foundation, 229 Moo 1, Chiang Saen, Chiang Rai 57150, Thailand. Email: jroberts@anantara.com

${ }^{\mathrm{d}}$ International College for Sustainability Studies, Srinakharinwirot University, 114 Sukhumvit 23, Wattana, Bangkok 10110, Thailand. Email: chutionsavini@gmail.com

${ }^{\mathrm{e}}$ Institute for Health Care \& Public Management, University of Hohenheim, Fruwirthstr. 48, Kavaliershaus 4, 70593 Stuttgart, Germany. Email: janmbauer@gmail.com

${ }^{\mathrm{f}}$ Conservation Ecology Program, King Mongkut's University of Technology Thonburi, 49 Soi Tienthalay 25, Bangkhuntien-Chaithalay Road, Thakham, Bangkhuntien Bangkok 10150, Thailand.. Email: tommasosavini@gmail.com

Corresponding author: Franziska K. Harich

E-mail address: harich@uni-hohenheim.de, f.harich@gmx.de

Tel.: +49 711459 23601; fax: +49 71145923629

\footnotetext{
Present address

${ }^{1}$ Department of Biodiversity Conservation and Ecosystem Management, Nelson Mandela African Institution of Science and Technology, Arusha, Tanzania

2 Department of Intercultural Communication and Management, Copenhagen Business School, Porcelænshaven 18A, 2000 Frederiksberg, Denmark
} 


\section{Abstract}

2 Elephants, the largest terrestrial mega-herbivores, play an important ecological role in 3 maintaining forest ecosystem diversity. While several plant species strongly rely on African 4 elephants (Loxodonta africana; L. cyclotis) as seed dispersers, little is known about the 5 dispersal potential of Asian elephants (Elephas maximus). We examined the effects of 6 elephant fruit consumption on potential seed dispersal using the example of a tree species 7 with mega-faunal characteristics, Dillenia indica Linn, in Thailand. We conducted feeding 8 trials with Asian elephants to quantify seed survival and gut passage times (GPT). In total, 91200 ingested and non-ingested control seeds were planted in soil and in elephant dung to quantify differences in germination rates in terms of GPT and dung treatment. We used survival analysis as a novel approach to account for the right-censored nature of the data obtained from germination experiments. The average seed survival rate was $79 \%$ and the mean GPT was $35 \mathrm{~h}$. The minimum and maximum GPT were $20 \mathrm{~h}$ and $72 \mathrm{~h}$, respectively.

14 Ingested seeds were significantly more likely to germinate and to do so earlier than non15 ingested control seeds $(P=0.0002)$. Seeds with the longest GPT displayed the highest germination success over time. Unexpectedly, seeds planted with dung had longer germination times than those planted without. We conclude that $D$. indica does not solely depend on but benefits from dispersal by elephants. The declining numbers of these megafaunal seed dispersers might, therefore, have long-term negative consequences for the recruitment and dispersal dynamics of populations of certain tree species. 


\section{Introduction}

With ongoing forest fragmentation and losses, the seed dispersal of some tropical plants is becoming increasingly hampered as populations of large seed dispersal agents are declining and their movements are being restricted (Corlett 2002). This is of concern for overall forest diversity as the dispersal of seeds away from the parent organism is an essential strategy used by plants to find suitable establishment sites of reduced competition, herbivore or pathogen attacks (Howe and Smallwood 1982; Harms et al. 2000; Willson and Traveset 2000; Corlett 2014). Dispersal mechanisms include abiotic drivers such as wind or water and biotic dispersal modes such as endo- or epizoochory, with vertebrates as dispersal agents (van der Pijl 1972; Burrows 1986; Murray 1986; Fleming and Kress 2011). A broad range of different animal species can serve as seed dispersers, including birds, bats, rodents, carnivores, primates and terrestrial herbivores (Howe 1986; Stiles 2000; Corlett 2014). Provided the seeds can survive the consumption process, frugivorous animals, particularly the large-sized animals, can disperse seeds over wide distances (Seidler and Plotkin 2006). Among large herbivores, elephants are noteworthy in playing a prominent role in maintaining tree diversity in forest ecosystems. With a diet comprising more than 350 different plant species, African forest elephants (Loxodonta cyclotis) consume the broadest spectrum of fruits of all extant elephant species (Blake 2002) while Asian elephants (Elephas maximus) reportedly forage on around 100 different plant species (Sukumar 1989; Chen et al. 2006; Campos-Arceiz et al. 2008a; Baskaran et al. 2010; Campos-Arceiz and Blake 2011).

Hence, the range of plant species consumed by elephants varies greatly across geographic regions as do their daily travel and, therefore, potential seed dispersal distances (Sukumar 1989). Forest elephants in Ivory Coast have been reported to cover 1-15 km / day, for an average of about $6 \mathrm{~km}$ / day (Theuerkauf and Ellenberg 2000) whilst in northern Congo their travel distance varied between 2 and 22 km / day (Blake 2002). However, the actual distances over which elephants can disperse seeds can be much larger, especially for large seeds, which can take several days to pass through the digestive tract (Powell 1997). Notably, travel and dispersal distances of up to $57 \mathrm{~km}$ over a period of three days have been recorded for elephants in the Congo (Blake et al. 2009). The maximum dispersal distance for Asian elephants varies with geographical conditions and can range from an estimated $4-6 \mathrm{~km}$ in Myanmar and 46 - $54 \mathrm{~km}$ in India, with $50 \%$ and $>80 \%$ of seeds being dispersed over $1 \mathrm{~km}$ distances from their origins, respectively (Campos-Arceiz et al. 2008b; Sekar et al. 2015). This implies that both African and Asian elephants could potentially disperse seeds over 
distances as large as $54-57 \mathrm{~km}$. In tropical forests such distances are much larger than the maximum dispersal distances of other seed dispersers. Distances can be more than seven times longer than the maximum dispersal distance for black-casqued hornbills (Ceratogymna atrata) in West Africa and about 43 times longer than the maximum recorded dispersal distance for gibbons (Hylobates mulleri $x$ agilis) in Borneo (Holbrook and Smith 2000; McConkey 2000). Asian elephants might, therefore, rank among the most important longdistance seed dispersal agents in Asia (Campos-Arceiz et al. 2008b).

Some trees have even adapted to this mode of dispersal, the so-called "megafaunalsyndrome” (Janzen and Martin 1982; Guimarães Jr. et al. 2008; Blake et al. 2009; CamposArceiz and Blake 2011). Dispersal syndrome refers to a general set of characteristics of fruits and seed traits which are associated with a particular mode of dispersal, e.g. the evolvement of large fruits and seeds that attract megafauna as consumers and dispersers (van der Pijl 1972; Janzen and Martin 1982; Howe 1985; Campos-Arceiz and Blake 2011). Several plants such as Balanites wilsoniana, Sacoglottis gabonensis, Irvingia gabonensis and Panda oleosa likely rely exclusively on African forest elephants as seed dispersal agents for spatial distribution, increased germination success and reduced germination time with associated reduced exposure to seed predators (White 1994; Cochrane 2003; Babweteera et al. 2007; Blake et al. 2009; Campos-Arceiz and Blake 2011). In contrast, no such obligate seed dispersal mutualism has been recorded for Asian elephants thus far and they seem to disperse fewer seeds from fewer tree species than their African forest elephant counterparts. This view might however be biased due to the overall poorer knowledge of Asian elephant nutritional ecology (Corlett 1998; Kitamura et al. 2007; Campos-Arceiz and Blake 2011; Corlett 2014). While the passage of seeds through the gut of an African elephant generally enhances germination probability, there is little comparable data for the Asian elephant. One experimental study that explored the influence of gut passage on seed germination in the Asian elephant was disturbed too early to draw firm conclusions (Kitamura et al. 2007) whilst a second study found negative effects for tamarind (Tamarindus indica) seeds after ingestion (Campos-Arceiz et al. 2008b). In the face of declining numbers of large mammals in Southeast Asia (Ripple et al. 2015), more insights into their importance for the dispersal of seeds of different tree species are necessary to assess threats to forest ecosystems. Results from Africa showed that the loss of elephants (and other large frugivores) negatively affects the recruitment of animal-dispersed tree species, thereby fostering the development of species-poor tree communities with abiotic dispersal modes (Blake et al. 2009). Animal- 
dispersed tree populations in contrast will likely face increased clustering, contraction of their geographic ranges and reduction in genetic variation if the numbers of their dispersal agents decline or vanish altogether (Cramer et al. 2007; Guimarães Jr. et al. 2008; Terborgh et al. 2008; Markl et al. 2012; Pérez-Méndez et al. 2015).

Also in Southeast Asia, defaunated forests are very likely to face declines in tree diversity over time (Brodie et al. 2009; Harrison et al. 2013; Caughlin et al. 2014). Large frugivores like tapirs (Tapirus indicus) can be effective dispersers for small-seeded plants but seem to be only limited substitutes for megafaunal seed dispersers (Campos-Arceiz et al. 2012). Even so, few detailed studies have experimentally tested the impacts of Asian elephant fruit consumption on seed dispersal efficiency and studies of their frugivory and seed dispersal potential are still rare (Campos-Arceiz and Blake 2011; Corlett 2014). However, Sekar et al. (2015) recently assessed the potential of domestic bovids as replacements for elephant seed dispersal in India and Sekar et al. (2013) investigated the ecology of Dillenia indica, which is known to be eaten by elephants.

We expand upon the studies of Sekar and Sukumar (2013) and Sekar et al. (2015) by using Dillenia indica as an exemplary megafaunal syndrome species to empirically (i) establish whether and to what extent the seeds survive gut passage, (ii) assess if the seeds that have passed through the elephant gut have a higher average germination rate than control seeds that have not, (iii) assess the effects of planting ingested and control seeds with or without elephant dung, and (iv) quantify the degree to which the gut passage time (GPT) affects the viability of seeds. With this study we also aim to highlight the importance of seed dispersal for overall forest diversity and general biodiversity conservation in the context of land-use changes.

\section{Materials and Methods}

\subsection{Study site}

The feeding and germination experiment was conducted in northern Thailand, in cooperation with the Golden Triangle Asian Elephant Foundation (GTAEF), located in the border area between Thailand, Myanmar and Laos (UNODC 2006; Chin 2009). The annual precipitation is about 1550 - $1650 \mathrm{~mm}$ with a peak from June to September and a dry season from December to March. The average daily temperature ranges from $25.8{ }^{\circ} \mathrm{C}$ to $27.7{ }^{\circ} \mathrm{C}$ (unpublished GTAEF records). The natural vegetation of Northern Thailand is characterized by a mosaic of evergreen and deciduous forest patches (Gardner et al. 2000). Elephants of the foundation are ex-street begging elephants rescued to a forest environment in Northern 
124 Thailand. They are partly kept in disturbed natural forest remnants, partly on grasslands in the

125 floodplains of the Ruak river, a tributary to the Mekong river, and partly in open barns. The 126 animals are sometimes used for touristic activities like riding and bathing, for an approximate 127 average of 3.5 hours and a maximum of 5 hours per day. For most of the remaining time, 128 elephants are allowed to roam in the forest or grassland, but are restricted by up to $30 \mathrm{~m}$ long 129 chains in the night.

\subsection{Study species}

132 Dillenia indica Linn. is an evergreen tree species of the family Dilleniaceae found throughout South and Southeast Asia, including the natural habitats of the Asian elephants (Van Steenis 1948; Abdille et al. 2005; Sekar and Sukumar 2013). The tree can grow up to $30 \mathrm{~m}$ in height (Van Steenis 1948; Gardner et al. 2000). Its fruits are large, around $10 \mathrm{~cm}$ in diameter, with many small seeds of about $6 \mathrm{~mm}$ in length that are protected by a hard mesocarp (Van Steenis 1948; Abdille et al. 2005; Sekar and Sukumar 2013). No significant arboreal frugivores were observed for $D$. indica; rodents as well as rhesus macaques (Macaca mulatta) are generally unable to access the seeds but some bovids (e.g. gaur Bos gaurus) can consume the fruits and seeds (Sekar and Sukumar 2013; Sekar et al. 2015). However, some individuals have difficulties dealing with the hardness of the mesocarp and elephants were found to eat more than twice as many fruits as the wild and domestic bovids combined (Sekar and Sukumar 2013). As the species is often found at watersides, it is not clear how much it relies on elephants relative to water for its seed dispersal (Van Steenis 1948; Datta and Rawat 2008; Sekar and Sukumar 2013).

\subsection{Feeding trials}

148 We selected six female elephants for our feeding trials, ranging in age from 6 to 35 years and in body weight from 2.9 to 3.5 tons. All elephants were born in captivity with the exception of the oldest one, for which no data were available. Elephants were seasonally allowed to range in a nearby forest with some restrictions, but not at the time of our experiments. Their normal diet of mainly grasses and various other feeds (e.g. bamboo, sugarcane, bananas) was maintained during the feeding trials. The animals were regularly checked by the foundation's veterinarian and were in good health. We offered the animals ripe $D$. indica fruits ad libitum. The elephants were fed one at a time to facilitate a detailed monitoring of their defecation time and to ensure enough manpower was available to retrieve all the dung and seeds. Before being fed to the elephants, the fruits were weighed and the number of seeds they contained 
estimated based on a regression model of seed number vs weight of control fruits (CamposArceiz et al. 2012). We monitored the elephants throughout the day and sieved the collected dung through a 2-mm wire mesh with water hoses. In the evenings, elephants were brought to a barn or to resting grounds. We collected the dung defecated in the nighttime in the early morning and assigned all seeds retrieved the mean time between when we stopped and resumed monitoring. We then dried the collected seeds and stored them in labeled paper envelopes for planting within one week of their collection date. We stopped dung collection when no further seeds were found in the dung over the course of at least 12 consecutive hours.

\subsection{Germination trials}

We counted seeds extracted from elephant dung and planted them in $2 \mathrm{l}$ pots with commercial potting soil at a nursery shaded with shadow nets. Five seeds were planted per pot and pots were regularly watered. We sequentially planted the seeds retrieved from the different study animals to minimize any potential negative effects of prolonged seed storage time on their germination ability. As the gut passage time (GPT) as well as the deposition of seeds in dung can impact seed survival and seedling growth (Lewis 1987; Nchanji and Plumptre 2001; Cochrane 2003; Campos-Arceiz et al. 2008b; Campos-Arceiz and Blake 2011) we included the two treatments 'GPT' and 'dung' in our germination experiments. For the GPT treatment, we assigned the seeds to different GPT categories to assess the effect of GPT on the germination rate or time to germination. We selected four categories: one for control and three GPT categories, according to the time of peak seed retrieval and whether the levels of seed loads in the dung piles were increasing or decreasing. The four categories were delineated as follows (i) control: fresh and non-ingested control seeds, (ii) short: all seeds retrieved within $30 \mathrm{~h}$ of GPT (GPT $\leq 30 \mathrm{~h} ; n=1878$ ), (iii) medium: all seeds retrieved after $30 \mathrm{~h}$ but within 48 h (30h < GPT $\leq 48$ h; $n=3797)$, and (iv) long: all seeds retrieved after 48 h (GPT > 48 h; $n=$ 581). For each of the six elephants, we planted a total of 200 seeds, 150 divided into the three GPT categories plus 50 fresh and non-ingested control seeds. In aggregate, 1200 seeds were planted. A total of 300 seeds were planted for the first GPT category plus another 300 seeds for the control treatment. We planted 410 seeds for the second GPT period while for the last GPT category, only 190 seeds were available due to the fast digestion of some elephants. Half of all the seeds planted in each of the three GPT categories were planted in pot soil only and the other half in combination with elephant dung. For the latter, the lower half of the pot was filled with pot soil and the upper half was filled with elephant dung, in which the seeds were placed. Germination and appearance of the first true leaves were monitored at least three 
times per week for a period of six months. We stopped monitoring 45 days after the last seed in a pot had germinated and no further germination event had occurred.

In addition to the single seed germination experiments, we planted two sets of whole fruits in two subsequent years. In the first year, we half-buried the fruits but recorded no germination success. In the second year we simply placed another 20 fruits on the ground, but unfortunately the experiment was interrupted by heavy rains and flooding before any germination event might have taken place. We therefore excluded this part of the experiments from all analyses.

\subsection{Statistical data analysis}

As we could not definitively declare the remaining non-germinated seeds as dead, we used survival analysis to calculate the germination rate as a function of time (Allison 1995; Hosmer and Lemeshow 1999). An important feature of the seed germination data is that the germination times are right-censored due to termination of the experiment before some seeds might still have germinated. For the latter, the exact germination time, thus, remains unknown and they are generally more likely to be censored. As a result, we used the censored and uncensored germination times, with the time in days from planting a seed to the date of germination of the seed as the response variable. We first estimated the distribution function of the seed germination times, i.e., the germination time distribution function (GTDF), and used this function to describe the germination times of the seeds subjected to the different treatments. When evaluated at time $t$ the GTDF yields the probability that a given seed from the population of experimental seeds will have a germination time that exceeds $t$. This can be expressed succinctly as

$$
G(t)=\operatorname{Pr}(T>t)
$$

where $G(t)$ is the germination distribution function (GTDF) and $T$ is the germination time of a randomly selected seed. We computed nonparametric estimates of the germination distribution function by both the product-limit and life-table methods, also commonly called the Kaplan-Meier and actuarial methods, respectively, in the SAS LIFETEST procedure (SAS Institute 2016). We also computed the closely related function, the cumulative distribution function $(\mathrm{CDF})$ :

$$
F(t)=1-G(t)
$$


227 We further computed the probability density function (PDF) of the germination time, defined as the derivative of $F(t)$, and denoted as $f(t)$ and the hazard function $h(t)$ defined as

We compared different germination time curves to determine whether the populations of seeds subjected to different treatments had identical GTDF functions. To do this, we used nonparametric $k$-sample tests based on weighted comparisons of the estimated hazard rate of the individual populations under the null and alternative hypotheses, where $k$ denotes the number of different treatment groups being compared. We conducted several statistical tests, differing in their weight functions, comprising the log-rank test, Wilcoxon test, Tarone-Ware test, Peto-Peto test, modified Peto-Peto test, and Fleming-Harrington $G_{\rho}$ family of tests. In the Wilcoxon test for homogeneity, pairs of the germination time functions were compared using the multiple-comparison method and the P-values for the paired tests (raw P-values) adjusted for multiplicity using simulation adjustment (simulated P-values). We performed log-rank and Wilcoxon test, respectively, to test the significance of the association of the germination variable with covariates (category of seeds, dung treatment and planting date of seeds). These tests were conducted by pooling over any defined strata, thereby adjusting for the stratum variables, and were carried out using the SAS LIFEREG procedure (SAS Institute 2016). If $T_{i}$ is a random variable denoting the germination time and $C_{i 1}, D_{i 2}$, and $t_{i 3}$ are covariates denoting the gut passage time category $(0,1,2,3)$, dung treatment $(0=$ without dung, $1=$ with dung) and planting date $\left(0,6,13,20,27,33\right.$ days from the start of the experiment) for the $i^{\text {th }}$ seed in the sample, then the model for the association between the germination time and the three covariates fitted by the LIFEREG procedure is

$$
\log _{e}\left(T_{i}\right)=\beta_{0}+\beta_{i, 1,0} C_{i, 1,0}+\beta_{i, 1,1} C_{i, 1,1}+\beta_{i, 1,2} C_{i, 1,2}+\beta_{i, 1,3} C_{i, 1,3}+\beta_{i, 2,0} D_{i, 2,0}+\beta_{i, 2,1} D_{i, 2,1}+\beta_{7}
$$

where $\varepsilon_{i}$ is a random error term and the $\beta$ s and $\sigma$ (scale) are parameters to be estimated. The $\log$ transformation of $T_{i}$ ensures that the predicted values of $T$ are positive regardless of the values of the covariates or their regression coefficients.

\section{Results}


260

261

262

263

264

265

266

267

268

269

270

271

272

273

274

275

276

277

278

279

280

281

282

283

284

285

286

287

288

289

290

291

292

293

The number of fruits consumed by individual elephants during the feeding trials averaged $15.2 \pm 6.2(n=76)$ and ranged between 8 and 25. The mean weight of a single fruit was 427.6 $\pm 75.4 \mathrm{~g}(n=188)$ whereas the average number of seeds per fruit was $168.9 \pm 63.5(n=112)$.

A total of 6253 ingested seeds were retrieved from the dung of five elephants over the entire course of the feeding trials. For the sixth elephant we could not ensure a continuous monitoring and therefore excluded this data set from survival rate calculations. The average seed survival rate for five elephants was $79 \%$, based on estimated numbers of seeds per fruit. However, the regression of the number of seeds against the weight of control fruits suggested a weak relationship $\left(r^{2}=0.12, P=0.000\right)$ albeit highly statistically significant and based on an approach used by other studies (Campos-Arceiz et al. 2012; Sekar et al. 2015). This implies that the reliability of the estimated survival rates of the ingested fruit seeds during their passage through the elephant gut (this should not be confused with the germination rate of the planted experimental seeds) was relatively low. The low reliability arises from the uncertainty associated with the total number of seeds in the ingested fruits estimated from the regression relationship.

The mean $( \pm 1$ SD) GPT was $35.3( \pm 9.3) \mathrm{h}$, with a mean minimum of $20( \pm 2.1) \mathrm{h}$ and a mean maximum of $72( \pm 8.6)$ h. Of the 1200 seeds planted across all the experimental treatments, $68 \%$ germinated and $96 \%$ of those that germinated developed first leaves over the course of the seven-month monitoring period. Until the censoring time at 167 days (plus 45 days monitoring without germination event), 61\% of control seeds germinated, 69\% for short GPT, $67 \%$ for medium GPT, and 80\% for long GPT, respectively. The mean germination success of seed loads from different elephants was $70 \%$ or 105 ( \pm 18.9 ) seeds per animal. The remaining non-germinated seeds were censored (supplementary data 1). The germination time curves for the four GPT categories (including the control), varied significantly in their expected mean times to germination $(Z=7.77$; $\mathrm{SE}=24052.94 ; P<0.0001$; Fig 2, supplementary data 2$)$ except for categories 1 and 2 that were $\operatorname{similar}\left(\mathcal{\chi}^{2}=0.4, P=0.9091\right.$, supplementary data 3$)$. Germination times were significantly longer for the control (80\%), short (29\%), and medium (26\%) categories, than for the long GPT category (Table 1; Fig. 2). Similarly, control seeds had longer expected germination times than seeds in the short $(Z=5.24$; SE $=0.0642 ; P<$ 0.0001), medium $(Z=5.96$; $\mathrm{SE}=0.0603 ; P<0.0001)$ and long $(Z=8.16$; $\mathrm{SE}=0.0720 ; P<$ 0.0001; Fig. 2, supplementary data 4) GPT categories. Dung treatment (yes, no) and planting date $(0,6,13,20,27,33$ days from the start of the experiment) had highly significant associations with germination time as shown by the nonparametric Wilcoxon and log-rank 
tests $(\mathrm{P}<0.0001$; supplementary data 5 and 6$)$. Results of the LIFEREG procedure of SAS

295 (SAS Institute 2016) provided evidence that GPT $\left(\chi^{2}=72.6, P<0.0001\right)$, dung treatment $\left(\chi^{2}\right.$ $296=62.5, P<0.0001)$ and date of planting $\left(\chi^{2}=140.9, P<0.0001\right)$ strongly influenced 297 germination time (supplementary data 7). The parameter estimates of the regression 298 coefficients showed that the expected germination time is $\left[100 \times\left(1-e^{-0.3567}\right)\right]=30 \%$ 299 significantly longer for seeds treated with dung than for the untreated seeds (Table 1, Fig.3). 300 The same applies to the median (or any other percentile) time to germination.

The percent increase in the expected germination time for each one unit increase in the planting date is expressed as $\left[100 \times\left(e^{0.02505}-1\right)\right]=2.54 \%$. This implies that each additional day that passes before the seeds are planted is associated with a $2.54 \%$ increase in the expected time to germination, given that the other covariates are held constant. This temporal influence on germination was likely due to the changing climatic conditions over seven months, with longer dry periods in between.

\section{Discussion}

4.1 Faster germination time for elephant-ingested seeds

In addition to the study of Sekar et al. (2015) in India, we used a larger sample size of elephants and experimentally evaluated the influence of elephant dung itself on seed germination. Furthermore, we propose and apply a different approach to analyzing germination data by using statistical methods for survival analysis to reduce the potential bias associated with censoring the time to germination of seeds. Our results show that $D$. indica benefits from being eaten, although it does not solely depend on elephants for germination (i.e., a large number of seeds also germinate without being eaten). Surviving post-germination is yet another challenge and the faster germination time for seeds ingested by elephants can be expected to be beneficial if it substantially reduces the risk of seed destruction by post dispersal predators (Schupp 1993; Traveset and Verdú 2002; Cochrane 2003). The environmental conditions of the establishing site as well as the type of seed dormancy additionally influence germination speed (Crawley 2000; Traveset and Verdú 2002). Elephant dung has so far been found to provide neutral or beneficial environmental conditions in the form of nutrients, humidity and protection from predation (Campos-Arceiz and Blake 2011). Surprisingly, we found that $D$. indica seeds planted with dung had a longer germination time than seeds planted without dung, which might have been due to the limited pot size and no interaction with surrounding soils and fauna. In natural conditions, the intraspecific 
competition of large amounts of seeds deposited in the same dung pile might reduce seedling success (Lewis 1987; Campos-Arceiz and Blake 2011). The seed load naturally depends on how many fruits the elephants consumed, which, in our study differed across individuals, with 25 fruits being the maximum amount eaten. Sekar et al. (2015) observed individual differences across elephants, ranging from 7 to 52 fruits of $D$. indica being eaten. Generally, for elephants in natural habitats it is well documented that $D$. indica is a welcome addition to their usual diet (Campos-Arceiz et al. 2008a; Datta and Rawat 2008; Sekar and Sukumar 2013), and the elephants in our study seem to conform with this observation.

\subsection{Germination success increases with gut passage time}

We found that $D$. indica seeds that had the longest gut passage time had the highest germination success. The gut passage can have positive, negative or neutral effects on seed viability (Campos-Arceiz and Blake 2011). In our study, ingested D. indica seeds, regardless of their GPT category, had a higher germination rate compared to non-ingested control seeds. One challenge in seed germination experiments is that observation time is often limited and potential later germination events might be missed. Several studies have addressed this challenge by testing whether the remaining non-germinated seeds contained a viable or a rotten embryo (e.g. Chapman et al. 1992; Nchanji and Plumptre 2003; Campos-Arceiz et al. 2008b) and/or by continuing monitoring until a certain time after the last seed has germinated (Campos-Arceiz et al. 2012; Sekar et al. 2015; our study). The risk of bias remains due to the potential censoring of data and wrongly pronouncing potentially viable seeds as non-viable. We used survival analysis to minimize both potential sources of bias (Allison 1995). The proportion of germinated seeds as a function of time allowed the comparison of germination success among the different categories at any given point in time until the censoring date and provided information on the category-specific speed of germination.

\subsection{Large dispersal distances through elephants}

Apart from the faster germination of ingested seeds, another benefit for $D$. indica from the seeds consumed by elephants might be the seed dispersal distances and their impacts on the seed shadow (the distribution of viable seeds around their source; Janzen 1971; Willson and Traveset 2000). Asian elephants have home ranges of 50 - $1000 \mathrm{~km}^{2}$, reflecting the large area across which they can alter or maintain plant composition in ecosystems (Sukumar 1989; Campos-Arceiz et al. 2008b; Sukumar 2006). The seed dispersal distance by elephants varies 
362

363

364

365

366

367

368

369

370

371

372

373

374

375

376

377

378

379

380

381

382

383

384

385

386

387

388

389

390

391

392

393

394

395

the digestive system (Powell 1997). Dillenia indica seeds ( $\sim \mathrm{mm}$ in size) are relatively small and, hence, remain in the digestive tract for a rather short time period; their maximum GPT of $72 \mathrm{~h}$ we found is much shorter than the maximum GPT of $114 \mathrm{~h}$, reported for tamarind seeds (T. indica), which are about twice as large in size (Campos-Arceiz et al. 2008b). Mean dispersal distances for the latter were found to be about 1-2 km in Myanmar and Sri Lanka, depending on the season (Campos-Arceiz et al. 2008b), while Sekar et al. (2015) recorded mean dispersal distances of about $3.5 \mathrm{~km}$ for D. indica, Artocarpus chaplasha, and Careya arborea in India. Tamarind seeds were negatively affected by the retention time in the gut (Campos-Arceiz et al. 2008b). In contrast, D. indica seeds in our study profited: the longest GPTs and, therefore, the largest potential dispersal distance had the highest germination success. Hence, our findings highlight $D$. indica's high adaption to and potential benefit from megafaunal dispersers.

\subsection{Other potential means of seed dispersal}

With decreasing numbers of elephants and other megaherbivores as seed dispersers, plants have to rely on alternative means of dispersal such as livestock, humans or water, which has been reported for D. indica (Van Steenis 1948; Donatti et al. 2007; Datta and Rawat 2008; Guimarães Jr. et al. 2008, Sekar et al. 2015). This might not apply for areas with longer dry periods, where smaller animals might contribute to seed dispersal (Sekar and Sukumar 2013). Elephants remove significantly more fruits than other animals such as bovids, macaques and rodents but all of these species were able to access the seeds once the mesocarp had softened (Sekar and Sukumar 2013). While removal does not necessarily lead to dispersal, rodents, for example, are known to store seeds, thereby sometimes contributing to dispersal (Forget et al. 2002; Hulme 2002; Vander Wall 2002). Also macaques can serve as effective seed dispersers but in several cases have negative impacts on germination and viability of some species depending on the temporal context (Albert et al. 2013; Tsuji 2014). Domestic bovids, on the other hand, are able to disperse a great number of seeds for some species as well, but do not reach the seed dispersal capacity of elephants (Sekar et al. 2015).

\subsection{Conclusion and conservation implications}

In times of climate change, a large dispersal area might become increasingly important as it might help in buffering off potential population losses due to adverse environmental conditions (Corlett and Westcott 2013). However, due to increasingly intensive land use and destruction of ecologically important forests, movements of large mammals are becoming 
396

397

398

399

400

401

402

403

404

405

406

407

408

409

410

411

412

413

414

415

416

417

418

419

420

421

422

423

424

425

426

427

428

429

increasingly impeded with the result that their seed dispersal potential might either rapidly decline or even disappear altogether. Large-seeded plant species in particular are at a greater risk of being negatively affected by selective logging and hunting as large seed-dispersing frugivores are often the first animals to vanish from disturbed forests (Markl et al. 2012). Plant species experiencing the loss of their main seed dispersing animal agents might suffer collapses in their recruitment and regeneration cycles (Guimarães Jr. et al. 2008; Blake et al. 2009). Likely consequences will be increased clustering of tree populations and lower dispersal distances with associated reductions in the overall geographic range as well as losses in genetic variation (Cramer et al. 2007; Guimarães Jr. et al. 2008; Terborgh et al. 2008; Markl et al. 2012; Pérez-Méndez et al. 2015). Changes in species composition are to be expected with particularly severe ecological shrinkage in isolated ecosystems (Hansen and Galetti 2009; Markl et al. 2012).

Our results show that $D$. indica does not solely depend on but seems to benefit from being eaten by elephants as ingested seeds were significantly more likely to germinate and to do so earlier than non-ingested control seeds. With this study we contribute to the understanding of the effects of Asian elephants' frugivory which has been much less researched than that of African ones (Campos-Arceiz and Blake 2011). While we still know relatively little about elephant seed dispersal, particularly in Asia, it is clear that elephants hold key functions in forest ecosystems. The megaherbivores shape ecosystems through their high food intake and by destroying vegetation through trampling or breaking, thereby acting as filters on tree recruitment and shifting balances of herbaceous and woody plants (Bakker et al. 2016; Malhi et al. 2016; Terborgh et al. 2016). They are likely helping to avert exceeding redundancy while maintaining plant diversity and thus further decline or local loss of elephants and other large herbivores would likely favor abiotically-dispersed species, leading to simpler plant communities (Blake et al. 2009; Campos-Arceiz and Blake 2011). The disappearance of elephants could further trigger cascading effects for overall system functioning through alterations in habitat and trophic structures, leading to changes in abundance or even extinction of other animal species down to potential deterioration of carbon storage and disturbances of nutrient cycles (Wolf et al. 2013; Bello et al. 2015; Malhi et al. 2016). Hence, their stringent protection will not only benefit the pachyderms themselves but also aid in conserving the habitat for a broad range of plant and other animal species, and ultimately sustaining the services such forests provide also for humankind.

\section{Acknowledgements}


430 We thank Richard Corlett, Ruichang Quan, Ling-Zeng Meng, Bai Zhilin and others from the

431 Xishuangbanna Tropical Botanical Gardens in China for their support in initializing this 432 study. We are very grateful to the Anantara Golden Triangle Elephant Camp and Resort and 433 the Golden Triangle Asian Elephant Foundation for their support and provision of their 434 facilities. We particularly thank Sophie Bergin, Kanokchai Beche, Virada Prabharasuk, 435 Thitibon Keratimanochaya Plotnik and six mahouts for their assistance in feeding and 436 germination experiments. Many thanks go to Samantha Chandranath Karunarathna from the 437 Mae Fah Luang University for his support. The National Research Council of Thailand 438 granted us the permit to conduct research in Thailand. This study was partly supported by the 439 German Federal Ministry of Education and Research (BMBF) within the framework of the 440 SURUMER (Sustainable Rubber Cultivation in the Mekong Region) project, under Grant 441 number FKZ 01LL0919. JOO was supported by the German Research Foundation (DFG, 442 Research Grant \# OG 83/1-1).

443

\section{Author contributions}

445 FKH., ACT., TS., CS. conceived and designed the study. FKH performed the experiments 446 with the support of JER. JOO, FKH, JMB analyzed the data. FKH, ACT, JOO wrote the 447 manuscript; other co-authors provided important editorial input.

\section{Compliance with ethical standards}

450

451 Conflict of Interest: The authors declare that they have no conflict of interest.

\section{Statement of human and animal rights}

454 All applicable institutional and/or national guidelines for the care and use of animals were 455 followed.

\section{References}

458 Abdille MH, Singh RP, Jayaprakasha GK, Jena BS (2005) Antioxidant activity of the extracts 459 from Dillenia indica fruits. Food Chem 90:891-896 doi: 460 http://dx.doi.org/10.1016/j.foodchem.2004.09.002 
461

462

463

464

465

466

467

468

469

470

471

472

473

474

475

476

477

478

479

480

481

482

483

484

485

486

487

Albert A, Hambuckers A, Culot L, Savini T, Huynen M (2013) Frugivory and seed dispersal by northern pigtailed macaques (Macaca leonina), in Thailand. Int J Primatol 34:170-193 doi:10.1007/s10764-012-9649-5

Allison PD (1995) Survival analysis using the SAS system: A practical guide. SAS Institute Inc., Cary, NC, USA

Babweteera F, Savill P, Brown N (2007) Balanites wilsoniana: Regeneration with and without elephants. Biol Conserv 134:40-47 doi: 10.1016/j.biocon.2006.08.002

Bakker ES, Gill JL, Johnson CN, Vera FWM, Sandom CJ, Asner GP, Svenning J (2016). Combining paleo-data and modern exclosure experiments to assess the impact of megafauna extinctions on woody vegetation. Proc Natl Acad Sci U S A 113:847-855 DOI 10.1073/pnas.1502545112

Baskaran N, Balasubramanian M, Swaminathan S, Desai AA (2010) Feeding ecology of the Asian elephant Elephas maximus linnaeus in the Nilgiri Biosphere Reserve, Southern India. Journal of the Bombay Natural History Society, 107(1), Jan-Apr 2010 107:3-13

Bello C, Galetti M, Pizo MA, Magnago LFS, Rocha MF, Lima RAF, Peres CA, Ovaskainen O, Jordano P (2015). Defaunation affects carbon storage in tropical forests. Science Advances 1:1-10 doi 10.1126/sciadv.1501105

Blake S, Deem SL, Mossimbo E, Maisels F, Walsh P (2009) Forest elephants: Tree planters of the Congo. Biotropica 41:459-468 doi: 10.1111/j.1744-7429.2009.00512.x

Blake S (2002) The ecology of forest elephant distribution and its implications for conservation. PhD dissertation, Institute of Cell, Animal, and Population Biology, University of Edinburgh, Edinburgh, Scotland.

Brodie JF, Helmy OE, Brockelman WY, Maron JL (2009) Bushmeat poaching reduces the seed dispersal and population growth rate of a mammal-dispersed tree. Ecol Appl 19:854-863 doi: 10.1890/08-0955.1

Burrows FM (1986) The aerial motion of seeds, fruits, spores and pollen. In: DR Murray (ed) Seed dispersal. Academic Press Australia, Australia, pp 2-47 

mahouts to explore the diet of work elephants in Myanmar (Burma). Ecological Research

491 Campos-Arceiz A, Larrinaga AR, Weerasinghe U, Takatsuki S, Pastorini J, Leimgruber P, 492 Fernando P, Santamaría L (2008b) Behavior rather than diet mediates seasonal differences in 493 seed dispersal by Asian elephants. Ecology 89:pp. 2684-2691 doi: 10.1890/07-1573.1

494 Campos-Arceiz A, Blake S (2011) Megagardeners of the forest - the role of elephants in seed 495 dispersal. Acta Oecol 37:542-553 doi: 10.1016/j.actao.2011.01.014

496 Campos-Arceiz A, Traeholt C, Jaffar R, Santamaria L, Corlett RT (2012) Asian tapirs are no 497 elephants when it comes to seed dispersal. Biotropica 44:220-227 doi: 10.1111/j.1744$498 \quad 7429.2011 .00784 . x$

499 Caughlin TT, Ferguson JM, Lichstein JW, Zuidema PA, Bunyavejchewin S, Levey DJ (2014) 500 Loss of animal seed dispersal increases extinction risk in a tropical tree species due to 501 pervasive negative density dependence across life stages. Proc R Soc B Biol Sci 282:1-9 doi: 502 10.1098/rspb.2014.2095

503 Chapman LJ, Chapman CA, Wrangham RW (1992) Balanites wilsoniana: Elephant 504 dependent dispersal? J Trop Ecol 8:275-283

505 Chen J, Deng X, Zhang L, Bai Z (2006) Diet composition and foraging ecology of Asian 506 elephants in Shangyong, Xishuangbanna, China. Acta Ecologica Sinica 26:309-316 507 doi:10.1016/S1872-2032(06)60006-1

508 Chin K (2009) The Golden Triangle: Inside Southeast Asia's drug trade, 1rst edn. Cornell 509 University Press, New York, USA

510 Cochrane EP (2003) The need to be eaten: Balanites wilsoniana with and without elephant 511 seed-dispersal. J Trop Ecol 19:579-589

512 Corlett RT (2014) The ecology of tropical East Asia, 2nd edn. Oxford University Press, 513 Oxford, UK 
514 Corlett RT, Westcott DA (2013) Will plant movements keep up with climate change? Trends

515 in Ecology \& Evolution 28:482-488 doi: http://dx.doi.org/10.1016/j.tree.2013.04.003

516 Corlett RT (2002) Frugivory and seed dispersal in degraded tropical East Asian landscapes.

517 In: DJ Levey, WR Silva and M Galetti (eds) Seed Dispersal and Frugivory: Ecology, 518 Evolution and Conservation. CAB International, Oxon, UK and New York, USA, pp 451-465

519 Corlett RT (1998) Frugivory and seed dispersal by vertebrates in the Oriental (Indomalayan) 520 region. Biological Reviews 73:413-448 doi: 10.1111/j.1469-185X.1998.tb00178.x

521 Cramer JM, Mesquita RCG, Williamson GB (2007) Forest fragmentation differentially affects 522 seed dispersal of large and small-seeded tropical trees. Biol Conserv 137:415-423 doi: 523 http://dx.doi.org/10.1016/j.biocon.2007.02.019

524 Crawley MJ (2000) Seed predators and plant population dynamics. In: M Fenner (ed) Seeds: 525 The Ecology of Regeneration in Plant Communities. CAB International, Wallingford, UK, pp $526 \quad 167-182$

527 Datta A, Rawat GS (2008) Dispersal modes and spatial patterns of tree species in a tropical 528 forest in Arunachal Pradesh, Northeast India. Tropical Conservation Science 1:163-185

529 Donatti CI, Galetti M, Pizo MA, Guimarães Jr. P.R. PR, Jordano P (2007). Living in the land 530 of ghosts: Fruit traits and the importance of large mammals as seed dispersers in the pantanal, 531 brazil. In: AJ Dennis, EW Schupp, RJ Green and DA Westcott (eds) Seed Dispersal: Theory 532 and its Application in a Changing World. CAB International, Oxfordshire, UK, pp 104-123

533 Fleming TH, Kress WJ (2011) A brief history of fruits and frugivores. Acta Oecol 37:521-530 534 doi: 10.1016/j.actao.2011.01.016

535 Forget PM, Hammond DS, Milleron T, Thomas R (2002) Seasonality of fruiting and food 536 hoarding by rodents in neotropical forests: Consequences for seed dispersal and seedling 537 recruitment. In: DJ Levey, WR Silva and M Galetti (eds) Seed dispersal and frugivory: 538 ecology, evolution and conservation. CABI Publishing, Wallingford, UK, pp 241-256

539 Gardner S, Sidisunthorn P, Anusarnsunthorn V (2000) A field guide to forest trees of northern 540 Thailand, 1st edn. Kobfai Publishing Project, Bangkok, Thailand 
541 Guimarães Jr. PR, Galetti M, Jordano P (2008) Seed dispersal anachronisms: Rethinking the

542 fruits extinct megafauna ate. PLoS ONE 3(3): e1745. doi:10.1371/journal.pone.0001745

543 Hansen DM, Galetti M (2009). The forgotten megafauna. Science 324:42-43 DOI 544 10.1126/science.1172393

545 Harms KE, Wright SJ, Calderón O, Hernández A, Herre EA (2000) Pervasive density546 dependent recruitment enhances seedling diversity in a tropical forest. Nature 404:493-495 547 doi:10.1038/35006630

548 Harrison RD, Tan S, Plotkin JB, Slik F, Detto M, Brenes T, Itoh A, Davies SJ (2013) 549 Consequences of defaunation for a tropical tree community. Ecol Lett 16:687-694 doi: $550 \quad$ 10.1111/ele.12102

551 Holbrook KM, Smith TB (2000) Seed dispersal and movement patterns in two species of 552 Ceratogymna hornbills in a West African tropical lowland forest. Oecologia 125:249-257 doi: 553 10.1007/s004420000445

554 Hosmer DW, Lemeshow S (1999) Applied survival analysis, 1st edn. Wiley, New York, USA

555 Howe HF (1986) Seed dispersal by fruit-eating birds and mammals. In: DR Murray (ed) Seed 556 dispersal. Academic Press Australia, Australia, pp 123-189

557 Howe HF (1985) Gomphothere fruits: A critique. Am Nat 125:853-865

558 Howe HF, Smallwood J (1982) Ecology of seed dispersal. Annu Rev Ecol Syst 13:201-228 559 doi: 10.1146/annurev.es.13.110182.001221

560 Hulme PE (2002) Seed-eaters: Seed dispersal, destruction and demography. In: DJ Levey, 561 WR Silva and M Galetti (eds) Seed dispersal and frugivory: ecology, evolution and 562 conservation. CABI Publishing, Wallingford, UK, pp 257-273

563 Janzen DH, Martin PS (1982) Neotropical anachronisms: The fruits the gomphotheres ate. 564 Science 215:19-27 doi: http://dx.doi.org/10.1126/science.215.4528.19

565 Janzen DH (1971) Seed predation by animals. Annu Rev Ecol Syst 2:465-492 doi: 566 10.1146/annurev.es.02.110171.002341 
567 Kitamura S, Yumoto T, Poonswad P, Wohandee P (2007) Frugivory and seed dispersal by 568 Asian elephants, Elephas maximus, in a moist evergreen forest of Thailand. J Trop Ecol 23:373 doi: 10.1017/S0266467407004026

570 Lewis DM (1987) Fruiting patterns, seed germination, and distribution of Sclerocarya caffra 571 in an elephant-inhabited woodland. Biotropica 19:50-56 doi: 10.2307/2388459

572 Malhi Y, Doughty CE, Galetti M, Smith FA, Svenning J-, Terborgh JW (2016). Megafauna 573 and ecosystem function from the pleistocene to the anthropocene. Proc Natl Acad Sci U S A 574 113:838-846 DOI 10.1073/pnas.1502540113

575 Markl JS, Schleuning M, Forget PM, Jordano P, Lambert JE, Traveset A, Wright SJ, 576 Böhning-Gaese K (2012) Meta-analysis of the effects of human disturbance on seed dispersal 577 by animals. Conserv Biol 26:1072-1081 doi: 10.1111/j.1523-1739.2012.01927.x

578 McConkey KR (2000) Primary seed shadow generated by gibbons in the rain forests of Barito 579 Ulu, Central Borneo. Am J Primatol 52:13-29 doi: 10.1002/1098580 2345(200009)52:1<13::AID-AJP2>3.0.CO;2-Y Murray DR (1986) Seed dispersal by water. In: DR Murray (ed) Seed dispersal. Academic Press Australia, Australia, pp 49-85

583 Nchanji AC, Plumptre AJ (2001) Seasonality in elephant dung decay and implications for 584 censusing and population monitoring in south-western Cameroon. Afr J Ecol 39:24-32 doi: 585 10.1111/j.1365-2028.2001.00265.x

Nchanji AC, Plumptre AJ (2003) Seed germination and early seedling establishment of some elephant-dispersed species in Banyang-Mbo Wildlife Sanctuary, south-western Cameroon. J Trop Ecol 19:229-237 doi: 10.1017/S0266467403003262

Pérez-Méndez N, Jordano P, Valido A (2015). Downsized mutualisms: Consequences of seed dispersers' body-size reduction for early plant recruitment. Perspect Plant Ecol Evol Syst 17:151-159 DOI 10.1016/j.ppees.2014.12.001

592 Powell JA (1997) The ecology of forest elephants (loxodonta africana cyclotis matschie 593 1900) in Banyang-Mbo and Korup forests, Cameroon with particular reference to their role as 594 seed dispersal agents, Ph.D. Dissertation. University of Cambridge, Cambridge, UK 
595 Ripple WJ, Newsome TM, Wolf C, Dirzo R, Everatt KT, Galetti M, Hayward MW, Kerley 596 GIH, Levi T, Lindsey PA, Macdonald DW, Malhi Y, Painter LE, Sandom CJ, Terborgh J, 597 Van Valkenburgh B (2015). Collapse of the world's largest herbivores. Science Advances 598 1:1-12 doi 10.1126/sciadv.1400103

599 Schupp EW (1993) Quantity, quality and the effectiveness of seed dispersal by animals. 600 Vegetatio 107-108:15-29 doi: 10.1007/BF00052209

601 Seidler TG, Plotkin JB (2006) Seed dispersal and spatial pattern in tropical trees. PLoS Biol 602 4:2132-2137 doi:10.1371/journal.pbio.0040344

603 Sekar N, Lee C, Sukumar R (2015) In the elephant's seed shadow: The prospects of domestic 604 bovids as replacement dispersers of three tropical Asian trees. Ecology 96:2093-2105 doi: $605 \quad 10.1890 / 14-1543.1$

606 Sekar N, Sukumar R (2013) Waiting for gajah: An elephant mutualist's contingency plan for 607 an endangered megafaunal disperser. J Ecol 101:1379-1388 doi: 10.1111/1365-2745.12157

608 Stiles EW (2000) Animals as seed dispersers. In: M Fenner (ed) Seeds: The Ecology of 609 Regeneration in Plant Communities. CAB International, UK, pp 111-124

610 Sukumar R (2006) A brief review of the status, distribution and biology of wild Asian 611 elephants Elephas maximus. International Zoo Yearbook 40:1-8 doi: 10.1111/j.1748$612 \quad 1090.2006 .00001 . x$

613 Sukumar R (1989) The Asian Elephant : Ecology and management, 1. Publ. edn. Cambridge 614 University Press, Cambridge

615 Terborgh J, Nuñez-Iturri G, Pitman NCA, Valverde FHC, Alvarez P, Swamy V, Pringle EG, 616 Paine CET (2008) Tree recruitment in an empty forest. Ecology 89:1757-1768 doi: $617 \quad 10.1890 / 07-0479.1$

618 Terborgh J, Davenport LC, Niangadouma R, Dimoto E, Mouandza JC, Scholtz O, Jaen MR 619 (2016). Megafaunal influences on tree recruitment in african equatorial forests. Ecography 620 39:180-186 DOI 10.1111/ecog.01641 
621 Theuerkauf J, Ellenberg H (2000) Movements and defaecation of forest elephants in the moist

622 semi-deciduous Bossematié Forest Reserve, Ivory Coast. Afr J Ecol 38:258-261 doi:

623 10.1046/j.1365-2028.2000.00240.x

624 Traveset A, Verdú M (2002) A meta-analysis of the effect of gut treatment on seed 625 germination. In: DJ Levey, WR Silva and M Galetti (eds) Seed dispersal and frugivory: 626 ecology, evolution and conservation. CABI Publishing, Wallingford, UK, pp 339-350

627 Tsuji Y (2014) Inter-annual variation in characteristics of endozoochory by wild Japanese 628 macaques. PLoS ONE 9:e108155 doi: 10.1371/journal.pone.0108155

629 UNODC (2006) Opium poppy cultivation in the Golden Triangle: Lao PDR, Myanmar, 630 Thailand. United Nations Office on Drugs and Crime, Wien, UNODC

631 van der Pijl L (1972) Principles of dispersal in higher plants, 2d ed. edn. Springer, Berlin

632 Van Steenis, C.G.G.J. (general editor) (1948) Flora Malesiana. series I, seed plants., Volume 633 4, Part 1. Noordhoff-Kolff N.V., Djakarta

634 Vander Wall SB (2002) Secondary dispersal of Jeffrey pine seeds by rodent scatter-hoarders: 635 The roles of pilfering, recaching and a variable environment. In: DJ Levey, WR Silva and M 636 Galetti (eds) Seed dispersal and frugivory: ecology, evolution and conservation. CABI 637 Publishing, Wallingford, UK, pp 193-208

638 White LJT (1994) Sacoglottis gabonensis fruiting and the seasonal movements of elephants in 639 the Lopé Reserve, Gabon. J Trop Ecol 10:121-125 doi: 10.1017/S0266467400007768

640 Willson MF, Traveset A (2000) The ecology of seed dispersal. In: M Fenner (ed) Seeds: The 641 Ecology of Regeneration in Plant Communities. CAB International, UK, pp 85-110

642 Wolf A, Doughty CE, Malhi Y (2013). Lateral diffusion of nutrients by mammalian 643 herbivores in terrestrial ecosystems. PLoS ONE 8 DOI 10.1371/journal.pone.0071352 
Table 1. Maximum likelihood parameter estimates for the model relating germination time to the gut passage time (GPT) categories (control, short, medium, long), dung treatment (yes, no) and date of planting seeds. The null hypothesis is that all the coefficients are $0 . \exp (\beta)$ is the estimated ratio of the expected (mean) germination times. $C L=95 \%$ confidence limits.

\begin{tabular}{llcccccc}
\hline Parameter & Level & $\exp (\boldsymbol{\beta})$ & $\boldsymbol{S E}$ & Lower $\boldsymbol{C L}$ & Upper $\boldsymbol{C L}$ & $\boldsymbol{\chi}^{2}$ & $\boldsymbol{P}$ \\
\hline Intercept & & 4.021 & 0.067 & 3.891 & 4.152 & 3662.7 & $<0.0001$ \\
GPT & Control & 0.588 & 0.072 & 0.447 & 0.729 & 66.6 & $<0.0001$ \\
& Short & 0.251 & 0.071 & 0.112 & 0.391 & 12.4 & 0.0004 \\
& Medium & 0.229 & 0.068 & 0.095 & 0.363 & 11.3 & 0.0008 \\
& Long & 0.000 & & & & & \\
Dung & Yes & -0.357 & 0.045 & -0.445 & -0.268 & 62.5 & $<0.0001$ \\
& No & 0.000 & & & & & \\
Date & & 0.025 & 0.002 & 0.021 & 0.029 & 140.9 & $<0.0001$ \\
Scale & & 0.746 & 0.020 & 0.708 & 0.786 & & \\
\hline
\end{tabular}




\section{List of Figures}

644 Figure 1. Mean proportion (red line) and 95\% confidence band (green shaded area) of 645 germinated seeds across all categories as a function of time to germination. Germination rate 646 =1- proportion of non-germinated seeds. The vertical dashed lines mark the beginning of 647 germination and the right-censoring date, respectively. Monitoring of seeds was continued for 64845 days after the date of the last germination event.

649 Figure 2. The proportion of germinated seeds as a function of time for the control group (not 650 ingested) and the three gut passage time (GPT) treatment groups (short: GPT $\leq 30 \mathrm{~h}$, medium: $65130 \mathrm{~h}<\mathrm{GPT} \leq 48 \mathrm{~h}$, long: GPT $>48 \mathrm{~h}$ ) and the pointwise 95\% confidence bands. Germination 652 rate $=1$ - proportion of non-germinated seeds.

653 Figure 3. The proportion of germinated seeds as a function of time since planting in days for 654 the seeds planted with dung and without dung and the 95\% pointwise confidence bands. 655 Germination rate $=1$ - proportion of non-germinated seeds. 


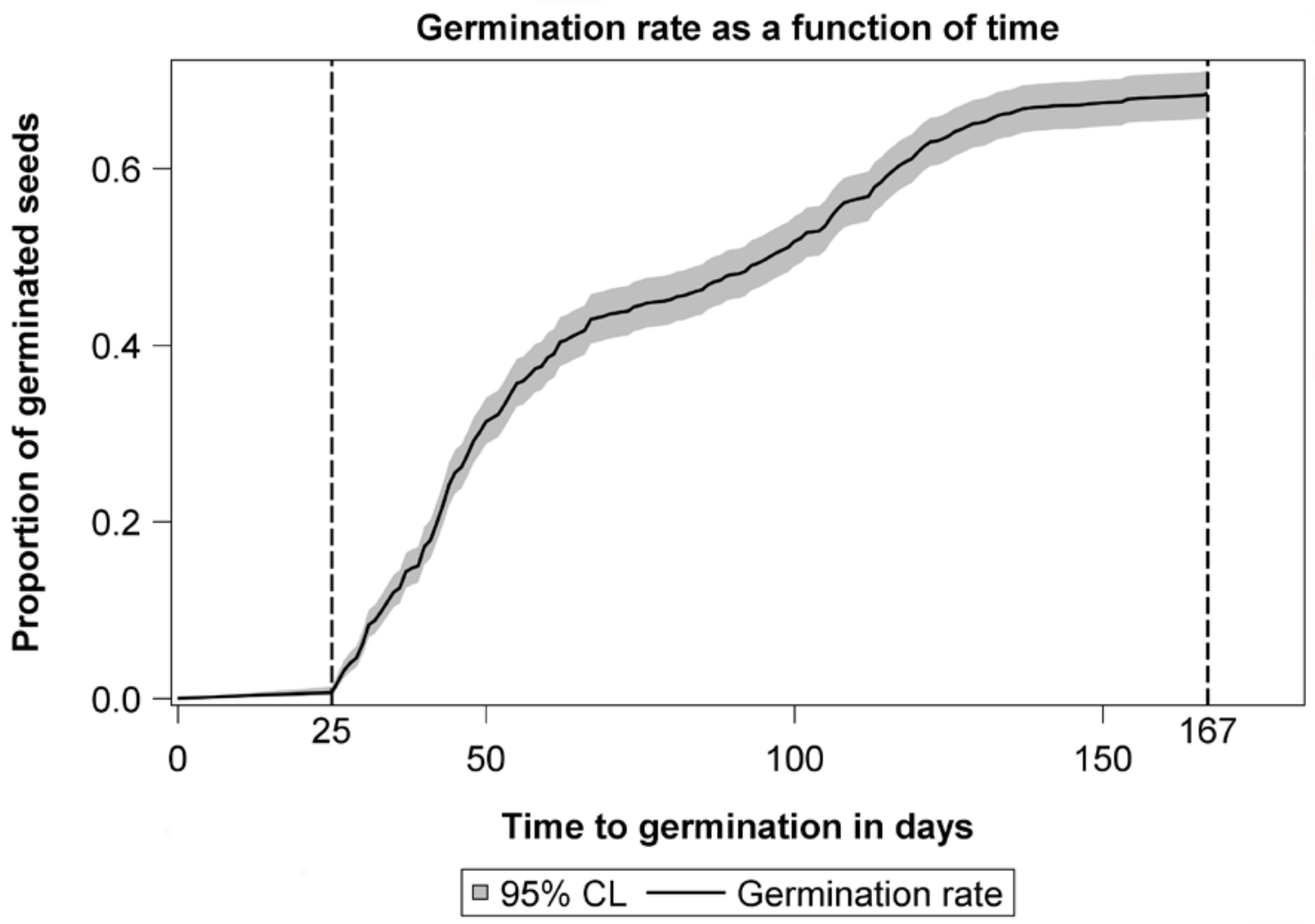

Figure 1 


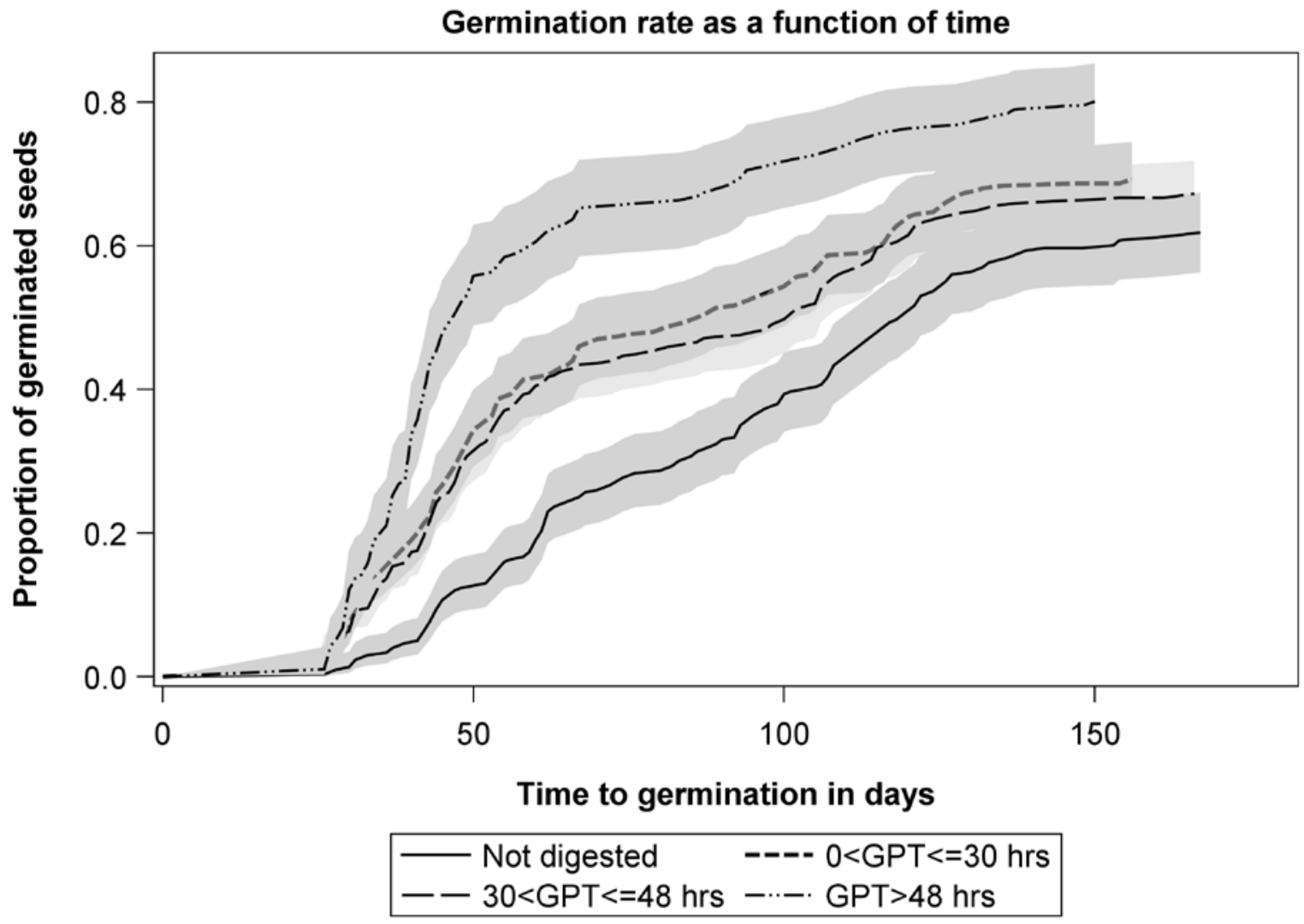

Figure 2 


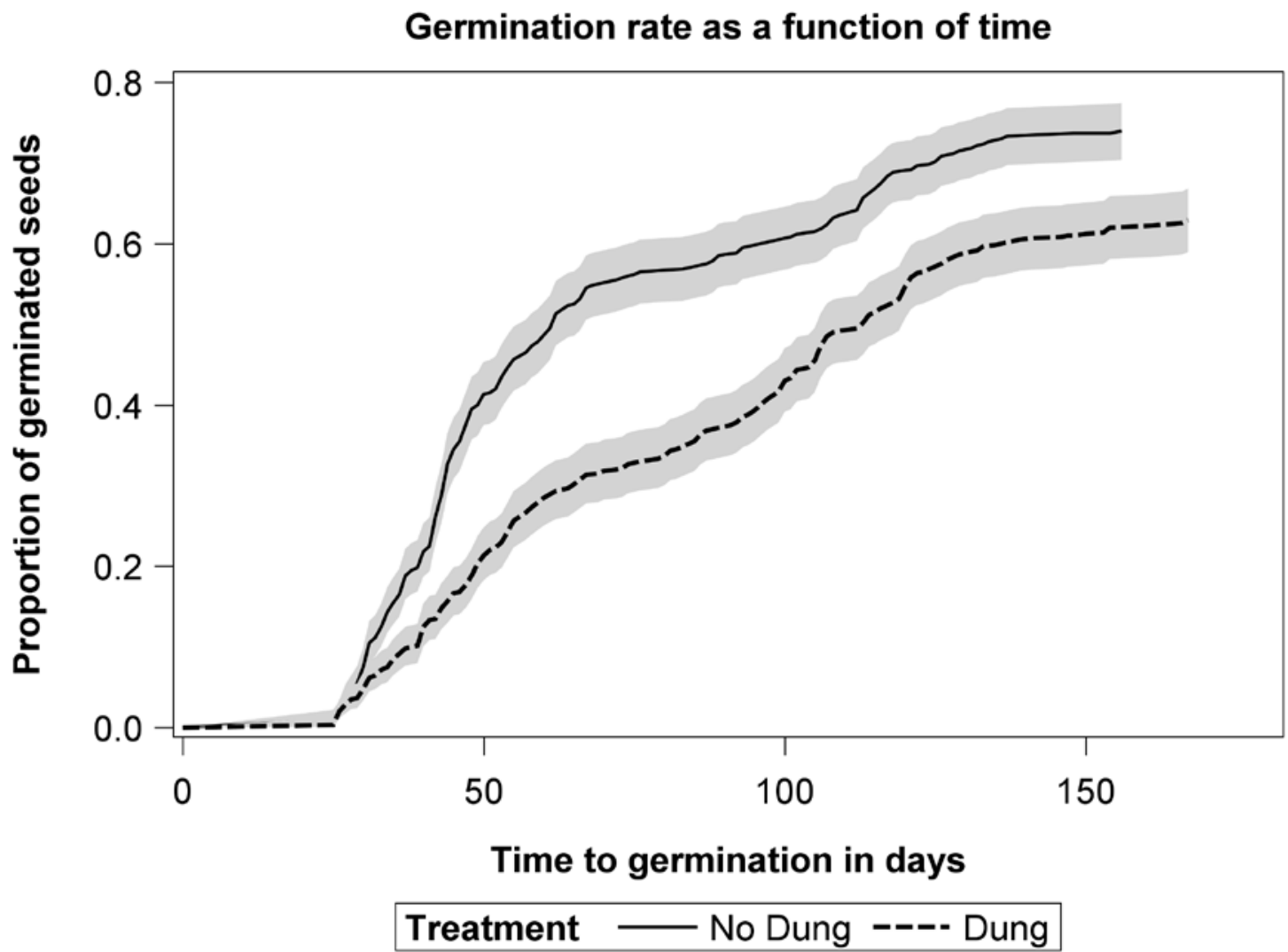

Figure 3 
